\title{
Declaration from the Calisia World Conference on Family Health 2019
}

\author{
Leif Edvard Aarø \\ Norwegian Institute of Public Health, Bergen, Norway \\ In collaboration with Witold Zatonski, Mateusz Zatonski and the Declaration Committee of the Calisia World Conference \\ on Family Health
}

ADDRESS FOR CORRESPONDENCE: Leif Edvard Aarø, Ph.D., Specialist Director, Division of Mental and Physical Health, Norwegian Institute of Public Health, P.O. Box 973, Sentrum, NO-5808 Bergen, Norway, e-mail: leea@fhi.no

Supplementary materials (slides) are available in Webappendix 17 at the journal's website: https://www.termedia.pl/Journal/Journal_of_ Health_Inequalities-100.

The Ottawa Charter on Health Promotion (1986) lists a number of prerequisites for good health. The one mentioned first is peace. The contributions to peace of the late Józef Glemp, Archbishop of Warsaw and Cardinal of the Roman Catholic Church, who led the Polish Church through the years of democratic transitions, were very important. He tried to unify, to compromise, and to promote dialogue. He contributed effectively to peace and public health, both in Europe and beyond.

The gaps between the regions of Europe (Western, Central, and Eastern) with regard to mortality, disease, risk factors, and health are well documented. The 2008 report Closing the health gap in European Union by Professor Zatonski et al. was the first comprehensive documentation of these differences. High levels of inequality exist also within countries. Better health and lower levels of risk are associated with higher levels of education, higher income, and having white-collar jobs. The persisting health gaps within and across countries in Europe contribute to reducing human capital and compromising economic and social progress.

These inequalities are largely caused by differences in risk factors for non-communicable diseases (NCDs) such as smoking, eating habits, alcohol use, physical inactivity, and differences in related biological risk factors. Poland may serve as an example. Health challenges in Poland include high levels of adult premature mortality and behavioural risk factors, in particular smoking and alcohol consumption.

One of the targets of the Sustainable Development Goals (SDGs) of the United Nations is to reduce premature mortality from NCDs by a third by 2030. Making healthy life expectancy more equitable is an important goal of the Action Plan for the Prevention and Control of Non-communicable diseases in WHO-Euro.

In order for countries to carry out effective public health action, a proper organisation and infrastructure for public health is needed. In many European countries such infrastructures barely exist, and in other European countries they are not sufficiently developed. A national infrastructure for public health should include: (1) strong political commitment, (2) proper legislation, (3) development of interventions, (4) coordination and crosssectoral collaboration (health in all policies), (5) surveillance, research, and evaluation, (6) orchestration of action, and (7) public health education and training.

The important role of political commitment and action of governments in establishing a strong public

...participants at the Calisia conference call on international organisations, governments, non-governmental organizations (NGOS), and all stakeholders to promote the establishment of strong infrastructures for public health and comprehensive action across sectors in all countries in order to prevent disease and promote health. Structural approaches such as taxation and legislation as well as community-based and family-based strategies targeting disadvantaged groups are important tools in reducing inequalities and inequities in health. Health must be for all, irrespective of location, gender, age, position, and circumstances. 
health infrastructure was emphasised at the Montevideo conference on NCDs in 2017 and by the WHO High-Level Commission on NCDs in 2018.

Socioeconomic inequalities in health have emerged through processes of change in which high-status population segments have been the first to benefit. Traditional health education-based interventions have contributed to SES inequalities in health. The use of structural approaches such as legislation and taxation will benefit societal groups more broadly, as will untraditional approaches such as combinations of community-based health impact assessment and development programmes targeting disadvantaged communities.
Families play an important role in peoples' lives, for adults as well as children and adolescents. Working directly with families can be an effective way of preventing the reproduction of poor health from one generation to the next.

Key words: Calisia Conference declaration, health inequalities, infrastructures for public health, community, family.

\section{DISCLOSURE}

The author reports no conflict of interests.

Leif Edvard Aarø, Ph.D., Specialist Director, Norwegian Institute of Public Health, and Professor of social psychology, University of Bergen 1987-2014. Among the initiators of the WHO Study on Health Behaviour in School-Aged Children. Aarø has evaluated behaviour change interventions in Norway and in sub-Saharan Africa. In 2008 he received the Golden Honorary Award of the Health Promotion Foundation of Poland.

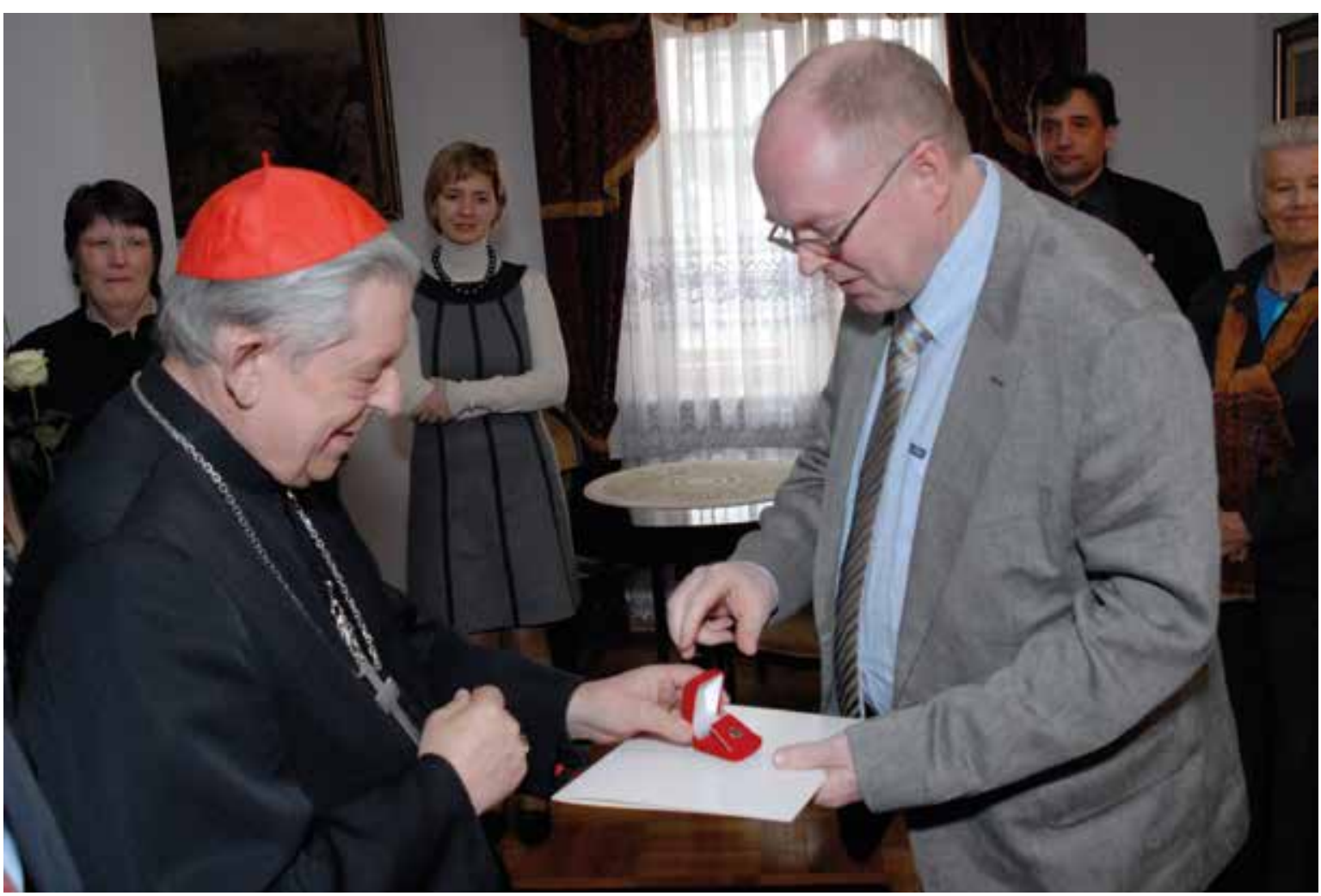

